Article

\title{
An Incubation System to Enhance Biogas and Methane Production: A Case Study of an Existing Biogas Plant in Umbria, Italy
}

\author{
Federica Liberti ${ }^{1}$, Valentina Pistolesi ${ }^{1}$, Mawaheb Mouftahi ${ }^{2}$, Nejib Hidouri ${ }^{2}$, \\ Pietro Bartocci ${ }^{3, *}{ }^{1}$, Sara Massoli ${ }^{1}$, Mauro Zampilli ${ }^{3}{ }^{-}$and Francesco Fantozzi ${ }^{3}$ \\ 1 CRB, Biomass Research Centre, University of Perugia, Strada S.Lucia Canetola, 06125 Perugia, Italy; \\ federica.liberti2@gmail.com (F.L.); pistolesi@crbnet.it (V.P.); massoli@crbnet.it (S.M.) \\ 2 Applied Thermodynamics Laboratory, National School of Engineers, Gabès University, Omar Ibn El Khattab \\ Street, Gabès 6029, Tunisia; mouftahimawaheb123@gmail.com (M.M.); n_hidouri@yahoo.com (N.H.) \\ 3 Department of Engineering, University of Perugia, Via G. Duranti 67, 06125 Perugia, Italy; \\ mauro.zampilli@unipg.it (M.Z.); francesco.fantozzi@unipg.it (F.F.) \\ * Correspondence: bartocci@crbnet.it
}

Received: 3 November 2019; Accepted: 28 November 2019; Published: 4 December 2019

\begin{abstract}
The pre-incubation of digestate and recycling of microbes inside a continuously stirred tank reactor (CSTR) are effective ways to optimize the anaerobic digestion process and improve the performance of biogas and methane production, also in existing biogas plants. In this study, a digestate incubation system using a nutrient mix to boost the activity of microbes was coupled to a CSTR to boost biogas and methane production. This system has been tested both on a lab scale and on an industrial scale. On a pilot scale, the system achieved an increase of $+16.47 \mathrm{v} \%$ in biogas production with respect to the conventional anaerobic digestion process, and an increase of $+2 \mathrm{v} \%$ in methane content (from $65.94 \mathrm{v} \%$ to $67.84 \mathrm{v} \%$ ). On an industrial scale, the use of this incubation reactor with a capacity of $1 \mathrm{~m}^{3}$ has led to an increase in methane yield of $12 \mathrm{v} \%$. This system allows to maintain the syntrophic relationship between acid-producing bacteria and methanogens and contemporary push the development of methanogens. Moreover, it is an economic system to be integrated into an existing biogas plant given the small volume and the simplicity of the incubation reactor.
\end{abstract}

Keywords: biogas; anaerobic digestion; maize silage; pig slurry; olive pomace; CSTR

\section{Introduction}

Anaerobic digestion (AD) is a biochemical process that consists of the degradation of organic matter by bacteria in the absence of oxygen. Anaerobic digestion is widely used to produce renewable electricity by the burning of biogas in internal combustion engines. Biogas is the final product of the anaerobic digestion, which consists of methane, carbon dioxide, and traces of other compounds, such as $\mathrm{NH}_{3}$, siloxanes, $\mathrm{H}_{2}, \mathrm{~N}_{2}$, and $\mathrm{O}_{2}$ [1]. Biogas can be used directly as fuel, in the combined heat and power gas engines, or it can be upgraded to biomethane. The effluent remaining after anaerobic digestion is a nutrient-rich substrate (digestate) and it can be used as fertilizer for agronomic applications [2].

Anaerobic digestion converts organic matter into biogas via four defined stages: hydrolysis, acidogenesis, acetogenesis, and methanogenesis. During hydrolysis complex organic substances (carbohydrates, proteins, and lipids) are decomposed by bacteria into soluble monomers, which during acidogenesis are converted into volatile fatty acids (VFA). The third step is acetogenesis, in which the VFA are mainly transformed in acetic acid by hydrogen-producing acetogens bacteria. In the fourth step, methanogenesis, the acetogenesis products are turned into methane by the synergistic action of various mesophilic bacteria [3]. Various factors influence methane production. The AD process 
performance and both: biogas production rate and composition are strongly correlated with the source of the organic substrate, with the process and operational conditions and with the type of technology used [4-6]. The energy yield changes by changing the substrate (i.e., sludge, agricultural waste, food waste, and wastewaters). It is of great importance to be aware of various substrate characteristics and their degradation mechanisms during the AD process. The carbohydrate and protein content can greatly influence methane production substrates with a high fat content would have a higher potential for the methanogenesis than substrates with the same quantity of carbohydrates. The configurations of the anaerobic digestion reactors and the biomass pretreatment methods are also factors affecting (effecting) digestion efficiency [7]. Anaerobic digestion systems are substantially divided into two types: one-stage AD systems and two-stage AD systems. In one-stage AD systems, all the four steps of the process (hydrolysis, acidogenesis, acetogenesis, and methanogenesis) are performed in a single reactor and this plant configuration is often associated with the acidification of the reactor, due to the formation of volatile fatty acids (VFAs) as inhibitory metabolites during acidogenesis and acetogenesis. Two-stage AD systems can increase (improve) the anaerobic digestion process stability, due to the separation of the four phases. In this plant configuration, the first three steps (hydrolysis, acidogenesis, and acetogenesis) are carried out in one bioreactor and the last step (methanogenesis) is carried out in a separate reactor. Two stage anaerobic digestion can increase anaerobic digestion process stability, because inhibitory metabolites (VFAs) produced in the first reactor are supplied to methanogens bacteria to improve methane production in the second one. This system not only gives a better biogas and methane production but also the production and collection of $\mathrm{H}_{2}$ in the first stage can improve the efficiency of the digestion process.

Anaerobic digestion systems have a variety of configurations, including conventional anaerobic reactors as continuously stirred tank reactors (CSTRs), anaerobic plug flow reactors (APFRs), anaerobic sequencing batch reactors (ASBRs), sludge retention reactors as up-flow anaerobic sludge bed reactors (UASBs), up-flow anaerobic solid-state reactors (UASSs), anaerobic baffled reactors (ABRs), internal circulation reactors (ICs), anaerobic contact reactors (ACRs), anaerobic membrane reactors as anaerobic filter reactors (AFs), anaerobic fluidized bed reactors (AFBRs), and expanded granular sludge blanket reactors (EGSBs) [7]. The CSTR is the most commonly used reactor and CSTRs have been effectively used to treat various types of agricultural residues, domestic and municipal wastewater, fruit and vegetable waste, grass, forest residues, live-stock manure, and many other by-products of various agricultural processes. Moreover, the CSTR is frequently used in research at full scale due to its simplicity in design and operation. Compared to other systems, the CSTR provides greater uniformity of process parameters, such as temperature, mixing, $\mathrm{pH}$, and substrate concentration. For these reasons the CSTR system is very suitable in real-scale applications. The CSTR system exists in different configurations depending on the reactor number. A single CSTR is inefficient due to the "short-circuit" and the consequent short hydraulic retention time [8,9]. The two stage CSTR system, where a short acidogenic step is followed by a long methanogenic step, is the most popular, due to simplicity of the system in design and operation and its high performance in terms of Chemical Oxygen Demand (COD) removal and biogas and methane productivity. Although the biodegradability of substrates may be improved in a two-stage CSTR, the separation of the acidogenic and methanogenic step could cause inhibition in the acidogenic reactor due to over production of hydrogen volatile fatty acids (VFAs) rather than acetate [10]. Furthermore, the two-phase reactor disrupts the syntrophic relationship between acid-producing bacteria and methanogens and the complete separation is difficult to be implemented and operated. It is necessary to adjust the condition of the effluent from the acidogenic reactor before feeding it to the methanogenic reactor, controlling $\mathrm{pH}$, volatile fatty acid (VFA) level, or nutrients [11,12]. In recent years, the introduction of a serial CSTR configuration on methanogenic reactors has attracted considerable attention as an alternative approach to overcome the abovementioned problems caused from one- and two-stage systems.

Kaparaju et al. [9] investigated the possibility of optimizing biogas production from manure using two methanogenic continuously stirred tank reactors (CSTRs) connected in series and the result 
showed that the serial CSTR improved biogas production. Boe and Angelidaki [13] compared a single thermophilic continuous-flow stirred tank reactor (CSTR) treating sewage sludge to serial CSTR reactors and the result showed than the serial CSTR increased biogas production by $11 \mathrm{v} \%$.

Liu et al. [8] investigated a new three-stage anaerobic digestion (TSAD) system combining an acidogenic stage (I), a first peak methanogenic stage (II), and a second peak methanogenic stage. TSAD achieved an increase in methane yield of 33.2-50.5 v\% with respect to that of the traditional one-stage and two-stage plants. However, the multi-stage reactor is an uneconomical solution, because it increases the capital cost of biogas plants.

The enhancement of any step of the AD process will lead to more methane generation and finally more energy produced. Hydrolysis is a rate-limiting process for anaerobic digestion and various methods are put forward to improve it, such as physical, chemical, electrical, and biological treatment. In electrical treatment, pulsed electric fields disrupt cellular membranes and induce higher permeation of biological cells [14]. Consequently, complex organic molecules are converted into simpler forms, easily degradable for acetogens bacteria. Inoculation or bioaugmentation with specific bacteria, which are capable to hydrolyze lignocellulosic biomass, is an environmentally friendly and cost-efficient biological pretreatment, which compared to other methods operates with less energy and chemicals furthermore it reduces the generation of inhibitory substances $[15,16]$. Thermal hydrolysis leads to the solubilization of organic compounds with the application of high temperature, pressure and the addition of steam [17]. Applying this technique, more fractions in the substrate become soluble and degradable so the hydrolysis is facilitated, by promoting fermentation bacteria. During acidification, soluble monomers are converted into short-chain fatty acids, such as acetic acid, which is the direct substrate for methanogens bacteria, as well as into propionic acid. To increase the production and the rate of conversion of monomers into acetic acid, different approaches can be considered, one of which is the use of substances that favor the bioconversion of carbohydrates, as for example cysteine [18], polycyclic aromatic hydrocarbons [19], and magnetite [20]. After the improvement of the first three stages, the methanogenesis stage is a key process to increase methane production. The use of additives, such as mineral compounds, oxide nanoparticles, bioaugmentation, and enzymes, encourages methane production as well as improves process stability. The addition of biochar also results in higher methane yield, due to its porous structure, which can absorb ammonia and immobilize methanogens [21-23]. Methods proposed for methane enhancement in recent studies have been tested mostly on a lab-scale. Development of a new type of reactor with specific hydraulic flow patterns at full scale, meeting the ecological requirements of the different anaerobic microbial populations, is a future research direction. Although there is some synergistic effect between acidogens and methanogens, instability of the ecological system will occur when acidogens and methanogens are present in the same reactor. Separation of the two kinds of bacteria in two reactors promotes the degradation rate and the stabilization of $\mathrm{pH}$ during the anaerobic biological treatment.

The use of two-phase reactors, which can improve the processing capacity due to the separation of the steps and through the use of different pretreatments, which can improve biogas production, methane concentration and is also beneficial for anaerobic digestion plants.

In this study, we tested a CSTR with the addition of an incubation reactor (where a nutrient mix is added) on both a lab and industrial scale, in which the substrate from the acidogenic fermenter reacts with the nutrients and then returns into the same reactor. This system allows to avoid disrupting the syntrophic relationship between acid-producing bacteria and methanogens and so balancing the production of volatile fatty acids and of acetic acid. The system proposed is an economic system to adopt for both one-stage and two-stage anaerobic digestion plants, given the reduced volume and the simplicity of the additional reactor. As far as the authors are concerned, the coupling of incubator systems to anaerobic digestion plants is a new aspect which is worthy of investigation. 


\section{Materials and Methods}

\subsection{Characterization of Substrate and Inoculum}

Samples of maize silage, olive pomace, and pig slurry were collected at an anaerobic digestion plant in Central Italy, operating under mesophilic conditions, in which they are daily used for feeding the digester. Samples of the substrate of the primary digester (i.e., the acidogenic reactor) were also taken. Because of their rapid acidification the samples were immediately analyzed and maintained in a refrigerated environment until they were used. The chemical-physical properties of the substrate and of the inoculum (Table 1) were measured by means of TGA 701 LECO (LECO Corporation, St. Joseph, MI, USA) (see Table 1) [24,25]. Moisture, ash, total solids and volatile solids content were measured according to References [26-28].

Table 1. Chemical and physical characteristics of the substrate and the digested matter (wet basis).

\begin{tabular}{cccccc}
\hline Substrate & Moisture (\%) & Volatile Solid (\%) & Ash (\%) & Fixed Carbon (\%) & Total Solid (\%) \\
\hline Primary substrate & $93.56 \pm 0.32$ & $5.22 \pm 0.02$ & $1.21 \pm 0.11$ & $0.01 \pm 0.01$ & $6.44 \pm 0.31$ \\
Maize silage & $57.67 \pm 0.11$ & $39.84 \pm 0.13$ & $1.25 \pm 0.07$ & $1.24 \pm 0.03$ & $42.33 \pm 0.44$ \\
Pig slurry & $97.94 \pm 0.24$ & $1.58 \pm 0.01$ & $0.48 \pm 0.05$ & $0 \pm 0.01$ & $2.06 \pm 0.02$ \\
Olive pomace & $80.3 \pm 0.22$ & $18.45 \pm 0.23$ & $0.92 \pm 0.09$ & $0.33 \pm 0.01$ & $19.07 \pm 0.51$ \\
\hline
\end{tabular}

\subsection{Nutrient Mix}

The nutrient mix was constituted by micronutrients and macronutrients required for the optimum microbial growth, and the composition of the mix used in the tests is shown below (Table 2). The micronutrients and macronutrients used are covered by a non-disclosure agreement with the company that has developed the incubation system.

Table 2. Chemical and physical characteristics of the micronutrients (wet basis).

\begin{tabular}{cccccc}
\hline Substrate & Moisture (\%) & Volatile Solid (\%) & Ash (\%) & Fixed Carbon (\%) & Total Solid (\%) \\
\hline Nutrient mix & $95.46 \pm 0.73$ & $1.13 \pm 0.03$ & $3.20 \pm 0.07$ & $0.21 \pm 0.01$ & $4.54 \pm 0.06$ \\
\hline
\end{tabular}

\subsection{Instruments and Methodology for Continuous Laboratory Reactor Test}

The effect of addition of the nutritional mix on the primary substrate was tested in a continuous laboratory reactor that faithfully reproduces the operation of the anaerobic fermenter on an industrial scale. This experimental campaign was preceded by the design, development, and testing of the system, aimed at assessing the suitability and functionality of the system itself.

The reactor (Figure 1) (Maufacted by BioBooster Srl, Italy) consisted of a cylindrical stainless-steel tank equipped with a supply duct placed on the upper part of the cylinder itself and a recirculation duct equipped with an external pump that allows the mixing of the substrate. On the upper part of the reactor two pipes were placed for the installation of a pressure data acquisition system and a biogas venting system. On the side wall of the cylinder a temperature sensor was placed. The reactor was also equipped with a valve and an outlet pipe for expelling the digested material. The reactor was emptied by a valve at the base of the cylinder itself. The heating system was electric with manual temperature adjustment. The maintenance of a constant temperature during operation was guaranteed by the presence of a layer of insulating material that was wrapped around the reactor and the recirculation duct. 


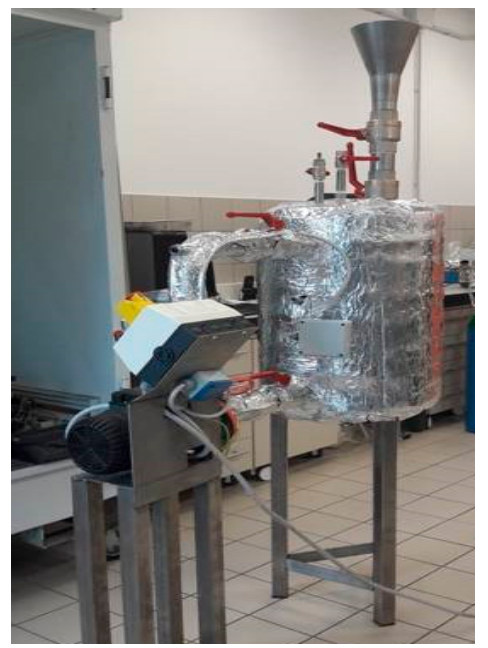

Figure 1. Continuous laboratory reactor.

The experimental test on the pilot plant was conducted in mesophilic conditions (temperature equal to $40^{\circ} \mathrm{C}$ ) through three distinct consecutive phases.

During Phase 1, the stabilization phase, $36.5 \mathrm{~L}$ of digested matter were loaded inside the reactor ( $32.77 \mathrm{~kg}$ considering a substrate density of $0.8977 \mathrm{~kg} / \mathrm{dm}^{3}$ ) for a period that guarantees the reach of the steady state. In the second phase (reactor feeding), once the substrate has been stabilized, the loading of the biomass started, taking into consideration the quantities loaded into the plant on a real scale. Phase 3 (reactor feeding with addition of nutritional mix) started once Phase 2 reached the steady state. In Phase 3 the digestate was mixed with nutrients and a small quantity of sucrose and incubated for 2 days in a hot bath at the same temperature of the reactor and then reloaded inside the reactor together with the new load of biomass. The addition of sucrose is carried out to activate the bacteria present in the nutrient mix and promote their growth. The quantities of nutrients and sucrose used in Phase 3 were equal, respectively, to $22 \mathrm{~mL}$ and $1 \mathrm{~g}$ per $500 \mathrm{~mL}$ of primary substrate. At each loading a charge of $1287 \mathrm{~g}$ of substrate was inserted into the reactor. This was composed by:

- $\quad 17 \mathrm{~g}$ of the incubated mixture;

- $\quad 350 \mathrm{~g}$ water and $350 \mathrm{~g}$ primary substrate;

- $\quad 570 \mathrm{~g}$ of newly charged biomass (composed by maize silage, olive pomace, and pig slurry in the same ratio used for Phase 2).

The mixtures loaded during Phases 2 and 3 are shown in Table 3.

Table 3. Composition of the mixtures loaded in the laboratory continuous reactor during Phases 2 and 3.

\begin{tabular}{ccc}
\hline Substrate & Phase 2 & Phase 3 \\
\hline Maize silage (g) & 380 & 380 \\
Olive pomace (g) & 80 & 80 \\
Pig slurry (g) & 110 & 110 \\
Water (g) & 350 & 350 \\
Primary substrate (g) & 350 & 350 \\
Incubated mixture (nutrient mix) & - & 17 \\
Total (g) & 1270 & 1287 \\
\hline
\end{tabular}

Biogas production was measured with pressure sensors (UNIK 5000, accuracy $0.04 \%$ and stability $0.05 \%$, manufactured by GE, USA), connected to a data acquisition system (NANODAC, Manufactured by Eurotherm by Schneider Electric, Frangarto, Italy). 
Excess biogas was vented and sampled with an air tight syringe (HAMILTON 1025 SL, manufactured by Hamilton Company, Reno, Nevada); gas composition was analyzed using a gas chromatograph (Varian Inc., Model CP-4900 commercialized now by Agilent Technologies, Santa Clara, CA, USA) equipped with 2 columns: a Molsieve 5A Backflush heated column $(20 \mathrm{~m} \times 0.53 \mathrm{~mm})$ (Manufactured by Agilent technologies, Santa Barbara, CA, USA) and a Pora PLOT U heated column $(10 \mathrm{~m} \times 0.53 \mathrm{~mm})$ (Manufactured by Agilent technologies, Santa Barbara, CA, USA). Argon and Helium were used as carrier gases. Injection temperature, column temperature and column pressure were set to $110^{\circ} \mathrm{C}, 120^{\circ} \mathrm{C}$, and $50 \mathrm{Psi}$, and $110^{\circ} \mathrm{C}, 150^{\circ} \mathrm{C}$, and $22 \mathrm{Psi}$, respectively, for Column 1 and Column 2 . During the experimental tests both the quantity and the quality of the biogas produced was monitored and methane content of the biogas was periodically analyzed.

\subsection{Anaerobic Digestion Plant}

To verify the effective influence of nutrients in biogas production, the experimental results obtained on a laboratory scale were compared with the real data obtained at the industrial scale plant.

The plant was characterized by a net electrical output of $999 \mathrm{kWe}$ and consisted of three components: two primary digesters and one secondary digester of working volume equal to $2000 \mathrm{~m}^{3}$ and $5000 \mathrm{~m}^{3}$, respectively. The primary digesters were covered, heated, and mixed to increase the reaction rate. The secondary digester was neither mixed nor heated, but was also used for storage of the biogas produced during the digestion process. The biogas plant configuration is presented in Figure 2.

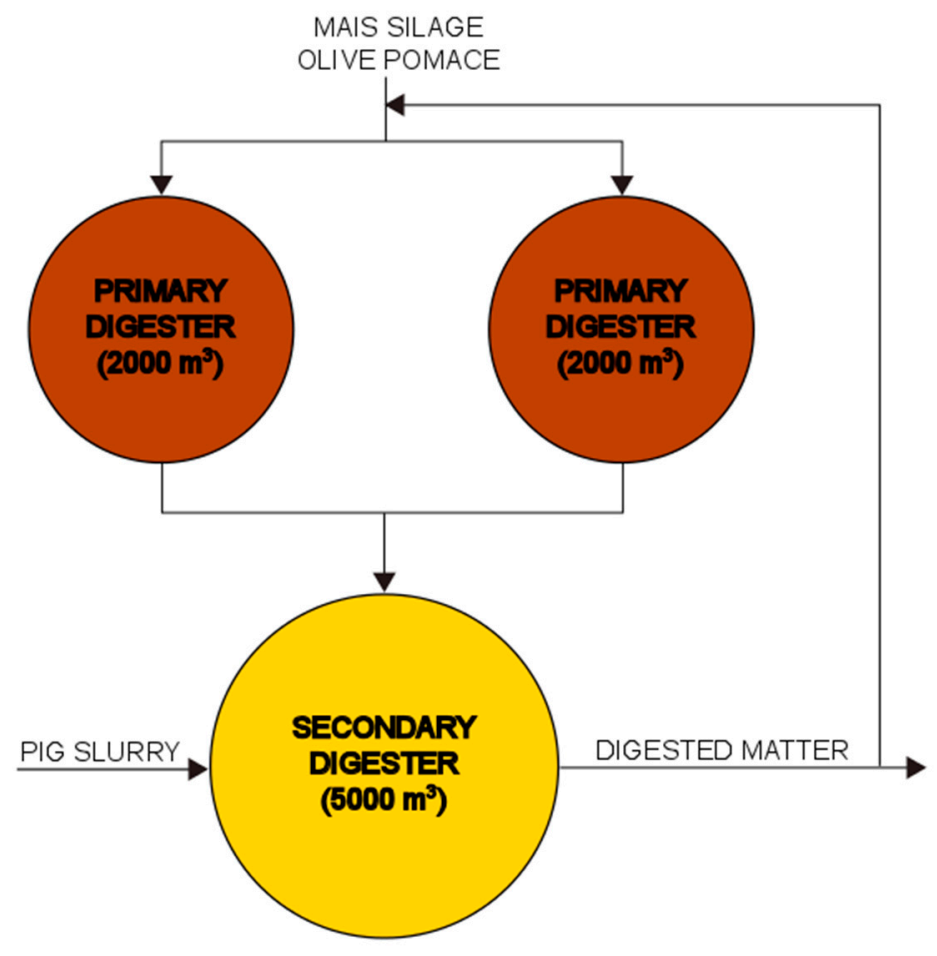

Figure 2. Biogas plant layout.

In particular, the increase in biogas production was checked by acquiring the daily electricity production for the years 2014 and 2016. The data for the year 2014 were considered representative of the production of biogas before the installation of the incubation system, while those for the year 2016 were considered representative of the biogas production obtained after the installation of the incubation system, which happened during the year 2015. In order to have comparable data, they were collected and also analyzed together with the daily loading plans, implemented during the years 2014 and 2016. In this way it was possible to relate the production of biogas to the actual quantity of volatile substances loaded in the primary fermenters. 
In particular, the operation of the incubation system consists of taking an aliquot of one cubic meter of substrate from the primary fermenter (about $0.05 \%$ of the entire reactor volume), adding the nutrients to the substrate, incubating the mixture for two days at the same temperature conditions of the plant and reintroducing it in the primary fermenter (Figure 3). The incubation aims at generating a substrate enriched with indigenous methanogenic bacteria, capable of improving the quality of the biogas and the efficiency of the degradation process.

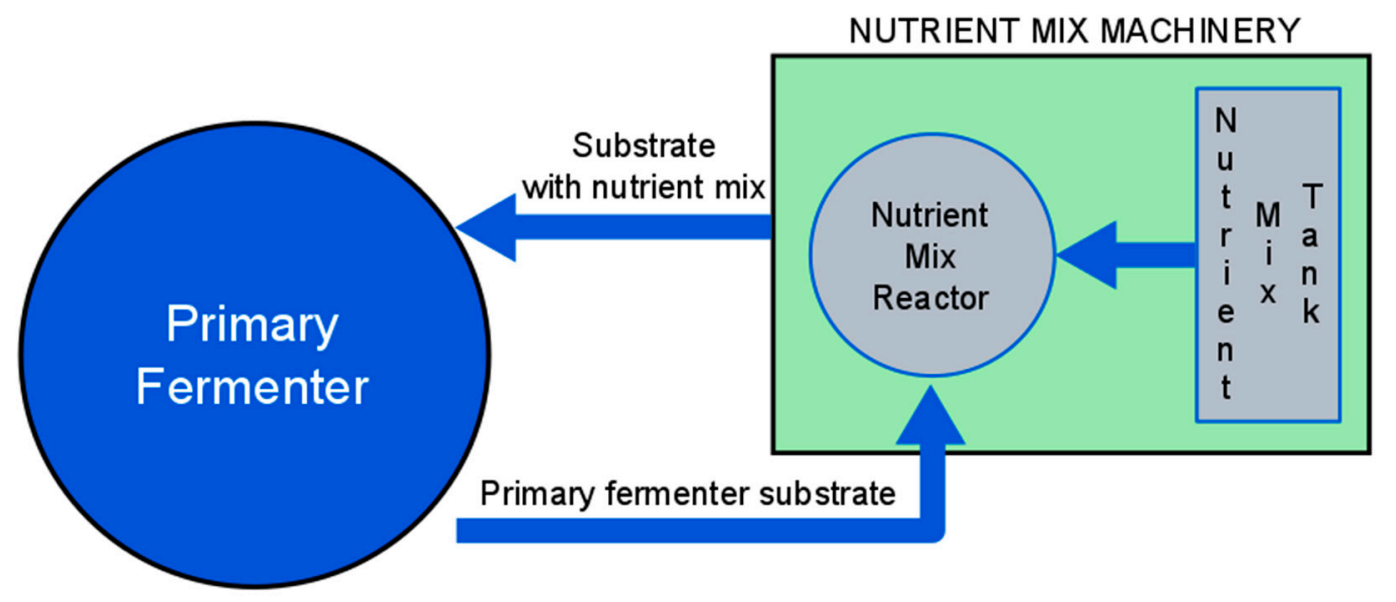

Figure 3. Layout of the anaerobic digestion (AD) system with a nutrient mix reactor.

The techno-economic analysis of the biogas plant was implemented with Retscreen software, comparing the situation of coupled anaerobic digestion and incubation with that of simple anaerobic digestion without incubation.

\section{Results and Discussion}

\subsection{Tests in the Continuous Laboratory Reactor}

The tests in the continuous laboratory reactor were repeated twice. Here we present the result of the first test. The first phase of biomass stabilization was necessary since the primary substrate, once arrived in the laboratory, was stored in the refrigerator at a temperature of $4{ }^{\circ} \mathrm{C}$. Before being loaded into the digester, it was kept at room temperature for about $24 \mathrm{~h}$ and then loaded into the reactor and gradually brought to a temperature of $40^{\circ} \mathrm{C}$. The stabilization phase ended after 19 days, a period in which biogas production was constant, indicating a balanced condition of microbial growth in the substrate. On the 19th test day, the daily production of biogas was equal to $0.0035 \pm 0.0002 \mathrm{Nm}^{3} / \mathrm{kgSV}$.

During phase 2 the mixture was loaded into the reactor every two days, simulating the loading conditions of the industrial scale biogas plant. In this phase the steady-state condition, characterized by constant daily biogas production, was reached after 23 days and the daily biogas production measured on the 42 nd test day was equal to $0.0137 \pm 0.0006 \mathrm{Nm}^{3} / \mathrm{kgSV}$. The continuous addition of fresh biomass inside the digester has increased the production of biogas, since new organic matrices have been introduced into the reactor.

Once the steady state conditions were reached during Phase 2, the mixture was loaded into the reactor, again every two days, and Phase 3 was started, characterized by the loading of biomass together with the mix of nutrients. In this phase the steady-state condition was reached after 28 days and the daily biogas production measured on the 70th test day was $0.0160 \pm 0.0007 \mathrm{Nm}^{3} / \mathrm{kgSV}$.

The biogas daily production and cumulative biogas and methane production during the overall lab reactor test are shown in Figure 4. 

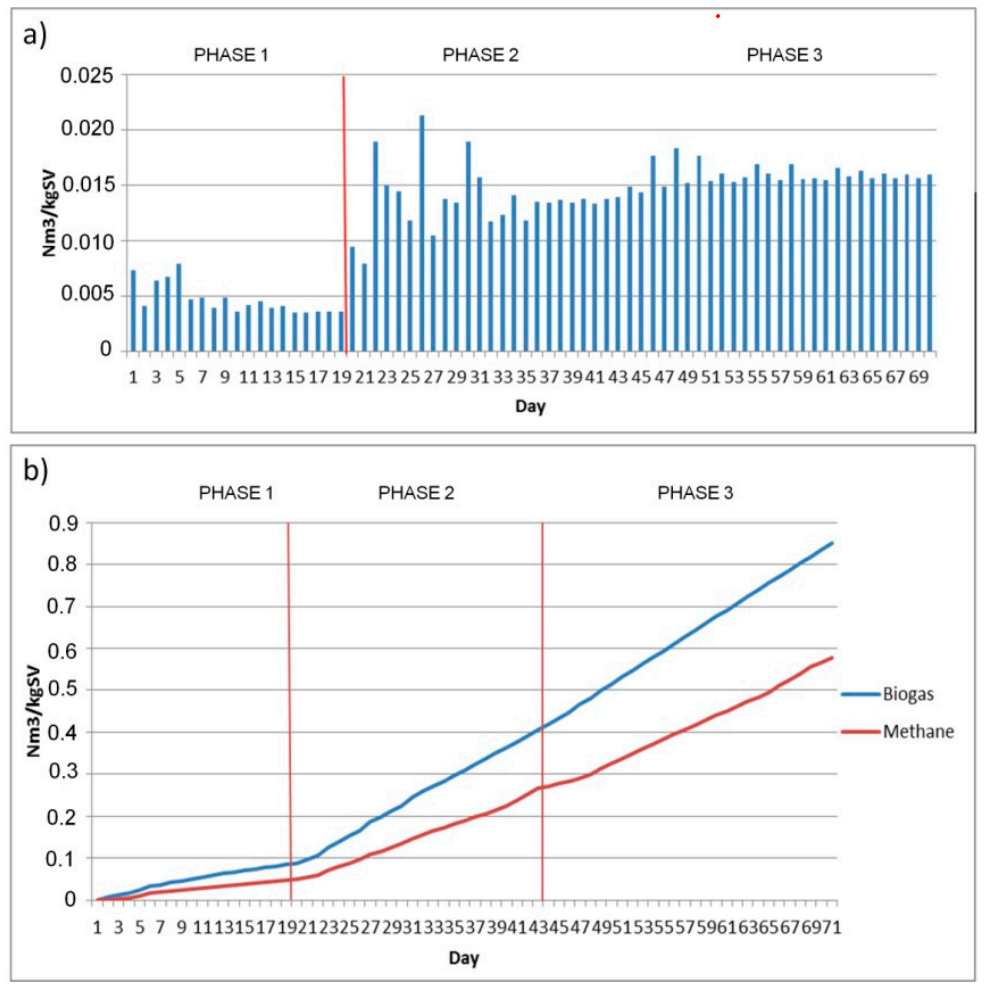

Figure 4. Daily biogas production (a) and cumulative biogas and methane production (b).

The influence of the nutrients is evident in the final loading phase, where the production of biogas from the biomass mixed with nutrients is constantly higher than the production obtained by loading biomass without the nutrients mix. In particular, Figure 5 shows the trend of the cumulative methane production of Phases 2 and 3, which highlights, with the help of trend lines, the different trend of methane production with and without the nutrients mix.

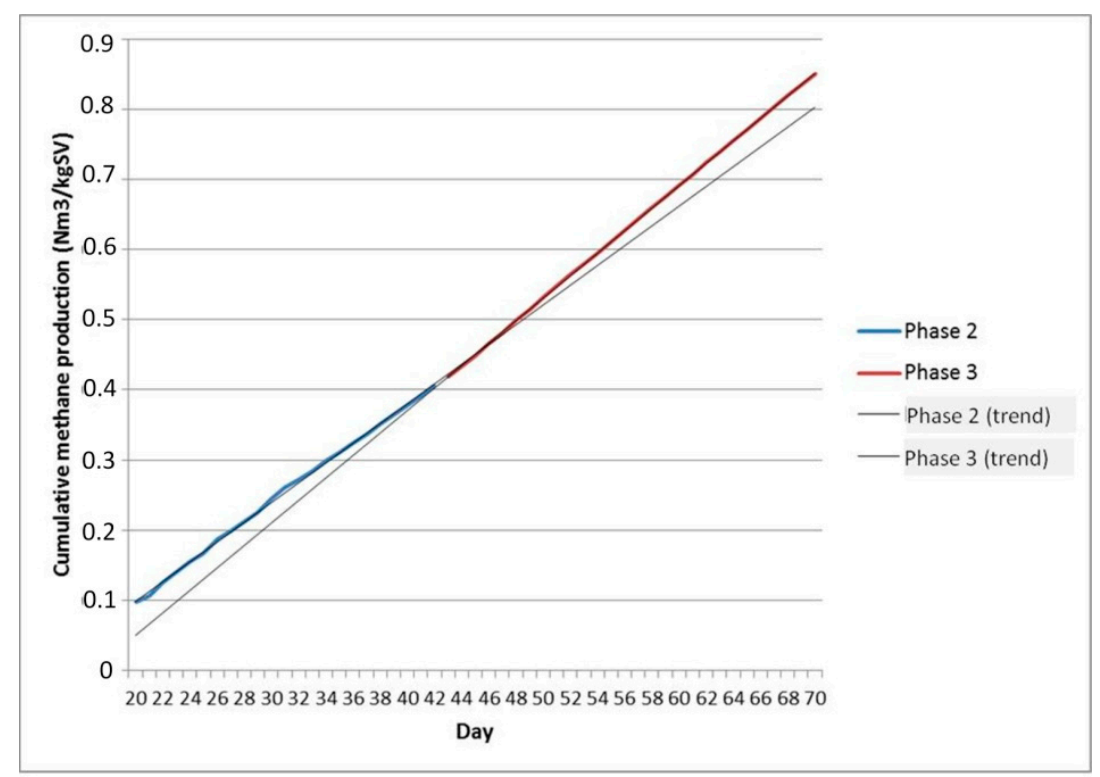

Figure 5. Cumulative methane production during Phases 2 and 3 and their linear trends. 
The trend lines show an increase in the slope and therefore an increase in the methane content in correspondence with the feeding of biomass added with the nutrients mix. During each loading phase the biogas composition was analyzed, and the methane percentages are shown in Table 4.

Table 4. Composition of the mixtures loaded in the laboratory continuous reactor during Phases 2 and 3 .

\begin{tabular}{lc}
\hline \multicolumn{1}{c}{ Phase } & Max \% CH4 \\
\hline 1 (stabilization) & $54.10 \pm 0.83$ \\
2 (reactor feeding) & $65.94 \pm 1.17$ \\
3 (reactor feeding with addition of nutritional mix) & $67.84 \pm 2.51$ \\
\hline
\end{tabular}

The addition of the nutrient mix in the reactor results in a considerable increase in the methane content in the produced biogas.

The increase is apparently due to an increase in methanogenic bacteria activity; acetoclastic and hydrogenotrophic bacteria in particular, which represent the final step in the chain of degradation of the organic matter. The addition of a nutrients mix has boosted the increase in methanogenic bacteria that transform the products of the metabolism of acetogens into methane and carbon dioxide. The addition of the nutrients mix and therefore the increase of the methanogenic bacterial charge would therefore allow to regulate the symbiotic process that exists between the different bacterial species: The acid bacteria produce the substrate for the methanogenic bacteria, while the methanogens, eliminating the products of acidogenic activity, maintain the right level of acidity of the substrate.

\subsection{Industrial Anaerobic Digestion Plant}

To verify the effective influence of nutrients and the advantages of the new incubation plant, the experimental results obtained on a laboratory scale were compared with the real data obtained at the industrial scale. In particular, this check was carried out by collecting and analyzing the daily electricity production for the year 2014 (before the use of the incubator with the nutrients mix) and the year 2016 (after the use of the incubation system). In order to make a reliable comparison, the loading plan for the year 2014 and 2016 was analyzed. From this analysis it was shown that during the year 2014 and the year 2016 a total of 25.902 tons and 25.091 tons of animal and vegetal biomass were loaded, respectively, in the same proportions tested on a pilot scale. The electricity production obtained in 2014 and the one obtained in 2016 are reported in Table 5 and the percentage increase in energy production has been calculated.

Table 5. Electricity production in 2014 and 2016.

\begin{tabular}{ccc}
\hline Electricity Production Year 2014 (kWhel) & Electricity Production Year 2016 (kWhel) & Increase (\%) \\
\hline $7,989,701$ & $8,075,900$ & 1.08 \\
\hline
\end{tabular}

After determining the electrical energy produced by the plant in the years considered, the electrical efficiency of the cogenerator ( $\mathrm{nel}=40.6 \%$ ), the calorific value of the methane $\left(35.88 \mathrm{MJ} / \mathrm{Nm}^{3}\right)$, and the amount of volatile substances added annually into the primary fermenters, it was possible to trace the annual methane yield. In particular, Table 6 reports for each year the methane yield.

Table 6. Electricity and methane production in 2014 and 2016.

\begin{tabular}{ccc}
\hline & Year 2014 & Year 2016 \\
\hline kWhel year & $7,989,701$ & $8,075,900$ \\
$\mathrm{Nm}^{3}$ methane/year & $1,974,488$ & $1,995,791$ \\
$\mathrm{Nm}^{3}$ methane/kgSV & 0.255 & 0.287 \\
\hline
\end{tabular}


Therefore, comparing the yield for 2014 with the value considered for the year 2016, an increase in methane production of around $12 \mathrm{v} \%$ was calculated.

\subsection{Economic Analysis}

The increase on biogas production and methane concentration can have important impact on the economic balance of the biogas plant. The data reported in Table 7 represent the main inputs used in the economic feasibility analysis.

Table 7. Capital expense (CAPEX) and operating expense (OPEX) of the biogas plant.

\begin{tabular}{cccc}
\hline Component & Value & Unit of Measure & Source \\
\hline CHP plant & 600 & $€ /$ MWel & {$[29]$} \\
Biogas plant & 600 & $€ /$ plant & {$[29]$} \\
Building and logistics plus & 2.6 & M€/plant & {$[29]$} \\
installations & 40,000 & $€ /$ plant & Assumed \\
Incubator & 0.030 & $€ /$ kWh & {$[30]$} \\
Maintenance & 45,000 & $€ /$ person & {$[29]$} \\
Labor & 11 & $€ / \mathrm{t}$ & Calculated \\
Biomass & 5 & $\%$ & {$[29]$} \\
Discount rate & 24 & $\%$ & {$[31]$} \\
Taxes & 2 & $\%$ & {$[32]$} \\
Debt interest & 50 & $\%$ & Assumed \\
Debt ratio & 20 & Years & {$[29]$} \\
Project life & 140 & $€ / \mathrm{MWh}$ & {$[33]$} \\
\hline Electricity export rate & & &
\end{tabular}

The biomass production costs were calculated assuming that the feedstock is mainly represented by maize silage, which is cultivated by the company which owns the biogas plant.

The cumulative cash flows for the anaerobic digestion plant, when coupled with the incubator, are presented in Figure 6.

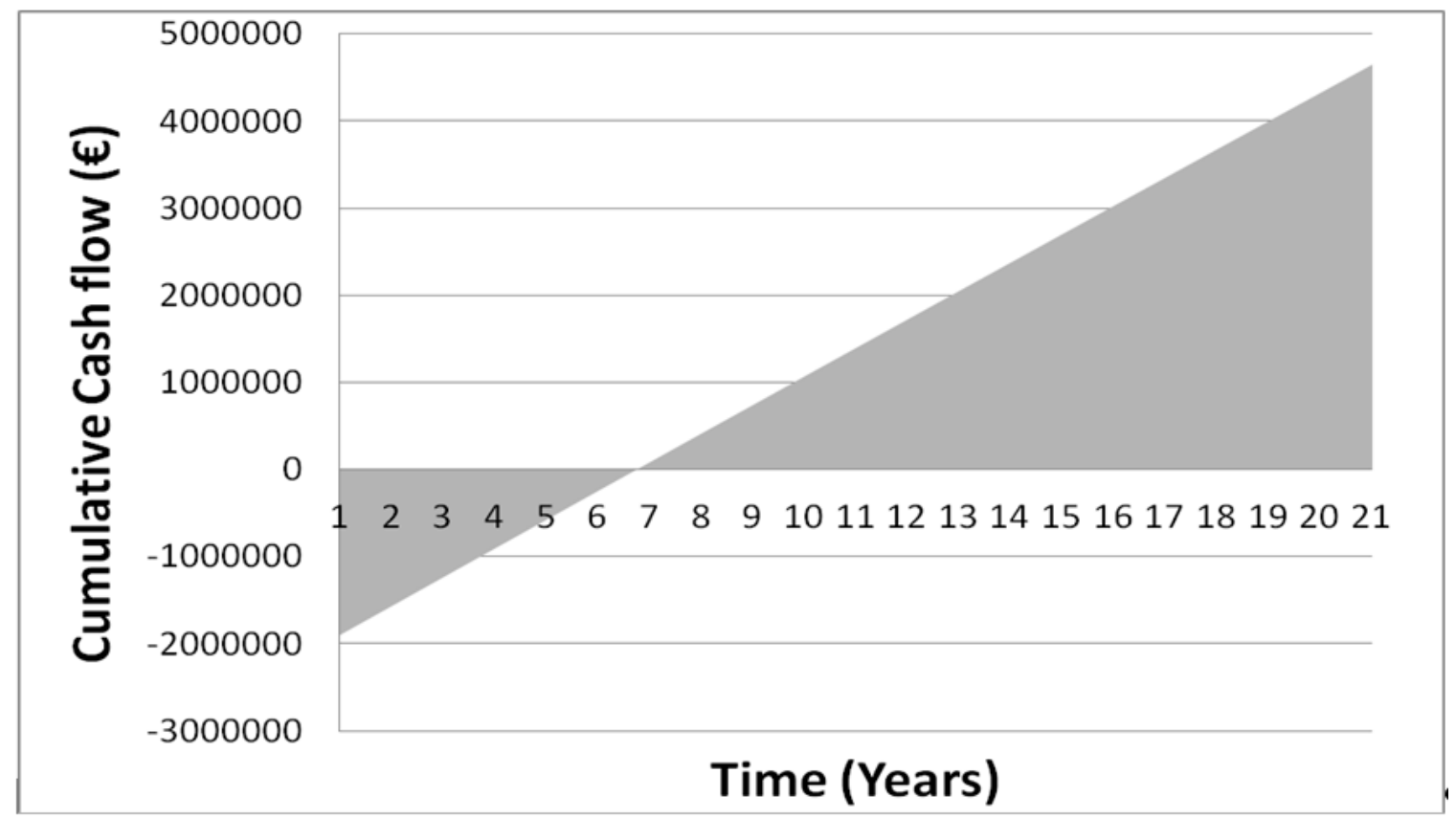

Figure 6. Cumulative cash flow of the anaerobic digestion plant coupled with the incubator.

Table 8 reports the comparison between the calculated financial indicators for the biogas plant with (AD + Incubator) and without (AD) an incubator. 
Table 8. Comparison between the financial indicators of the plant with (AD + Incubator) and without (AD) an incubator.

\begin{tabular}{cccc}
\hline Indicator & $\begin{array}{c}\text { Unit of } \\
\text { Measure }\end{array}$ & $\begin{array}{c}\text { Anaerobic Digester + } \\
\text { Incubator }\end{array}$ & $\begin{array}{c}\text { Anaerobic } \\
\text { Digester }\end{array}$ \\
\hline Pre-tax Internal Rate of Return-equity & $\%$ & 23.7 & 19.6 \\
Pre-tax Internal Rate of Return -assets & $\%$ & 10.3 & 7.9 \\
After-tax Internal Rate of Return -equity & $\%$ & 16.3 & 13.0 \\
After-tax Internal Rate of Return -assets & $\%$ & 5.8 & 3.6 \\
Simple payback & $\mathrm{yr}$ & 6.6 & 7.6 \\
Equity payback & $\mathrm{yr}$ & 5.8 & 7.0 \\
Net Present Value (NPV) & $€$ & $2,168,544$ & $1,457,326$ \\
Annual life cycle savings & $€ / \mathrm{yr}$ & 174,010 & 116,940 \\
Benefit-Cost (B-C) ratio & - & 2.13 & 1.77 \\
Debt service coverage & - & 4.93 & 4.30 \\
Energy production cost & $€ / \mathrm{MWh}^{\mathrm{H}}$ & 113.86 & 120.74 \\
Greenhouse Gases reduction cost & $€ / \mathrm{tCO}$ & $(107)$ & $(79)$ \\
\hline
\end{tabular}

The calculations show that pre-treatment systems, which are able to increase biogas production and give higher methane concentration, can repay their investment quite easily.

Figures 7 and 8 deal with the sensitivity analysis on payback. The black bars represent the cases with an equity payback value higher than 6 .

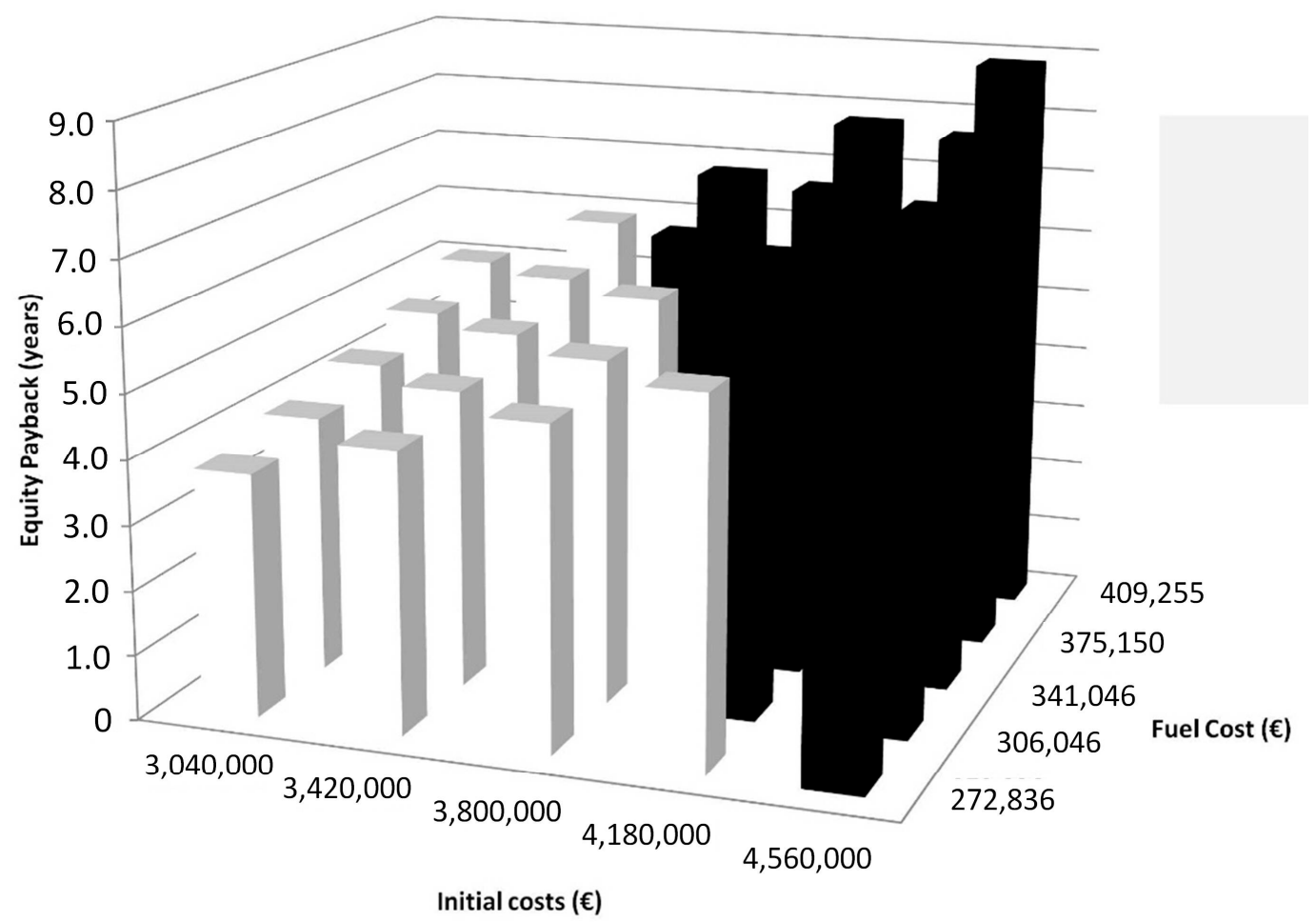

Figure 7. Sensitivity analysis on payback period by varying initial costs and fuel costs.

Figure 7 is based on the variation of two sensitivity factors: initial investment and fuel cost. The maximum variation inserted in the Retscreen software is equal to $20 \%$. Figure 8 is based on the variation of initial costs and electricity export rate.

Figures 9 and 10 show the results of risk analysis on equity payback. Figure 9 presents the seven most impacting factors on equity payback, ranked by decreasing order of importance. 


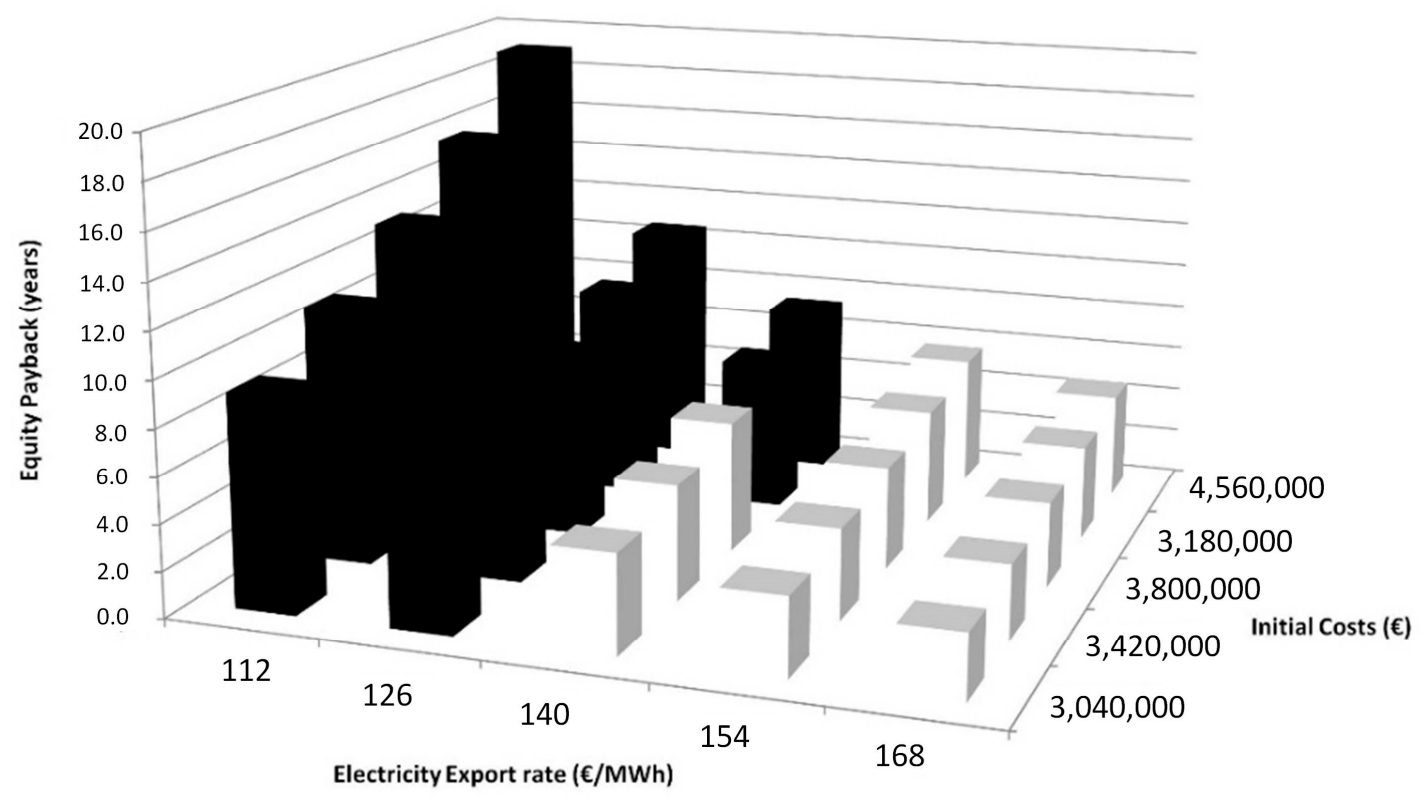

Figure 8. Sensitivity analysis on payback period by varying electricity export rate and initial costs.

Impact - equity payback

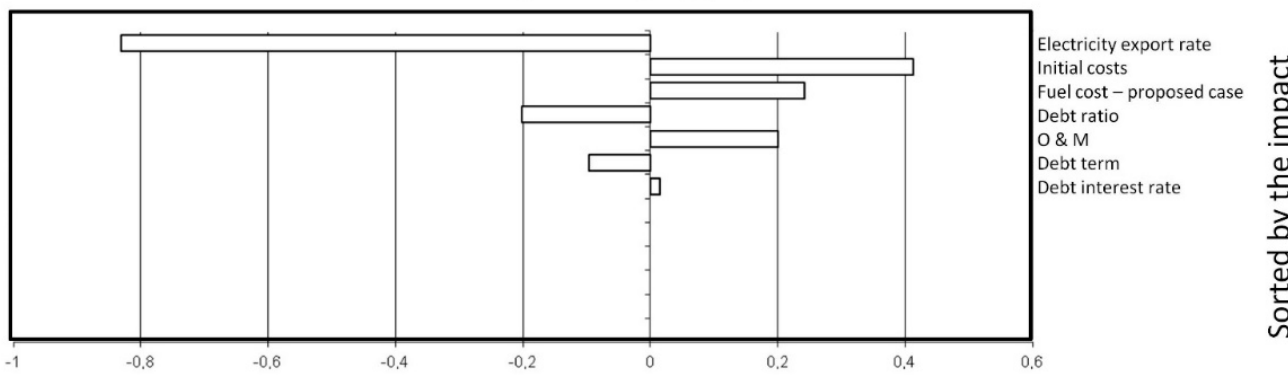

Relative Impact (standard deviation) of parameter

Figure 9. Relative impact of parameters on the equity payback.

Distribution - Equity payback

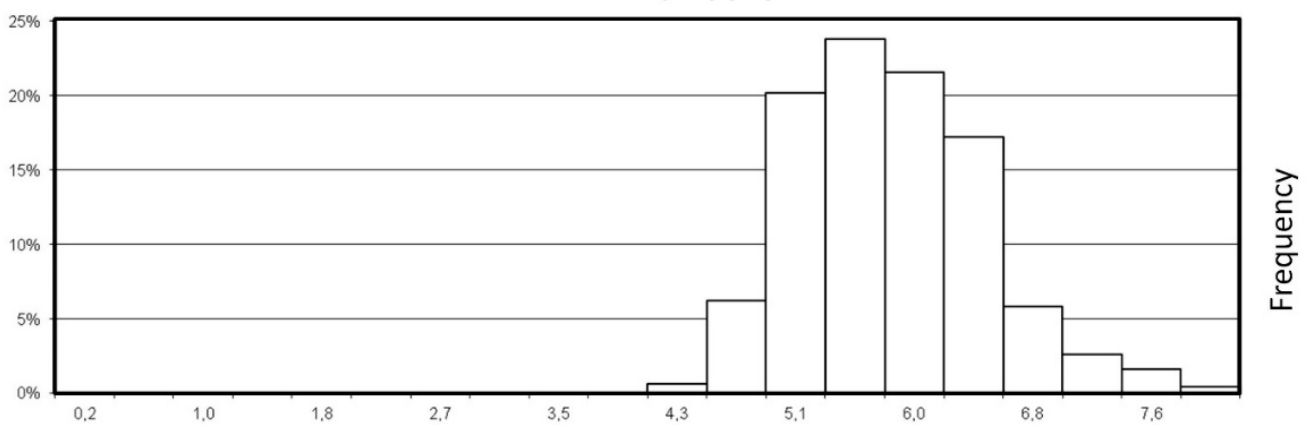

Figure 10. Distribution analysis of equity payback through Monte Carlo analysis.

Figure 10 shows the distribution analysis of equity payback, considering a $0 \%$ level of risk. It can be seen that the average value for the equity payback is about 5.8. The maximum value is about 8.3.

\section{Conclusions}

This study reports the results of experimental tests of anaerobic digestion on a laboratory and industrial scale, aimed at verifying and quantifying the increase in the biological efficiency of the anaerobic digestion process, in terms of biogas production and/or methane content, deriving from the 
use of a mix of nutrients and sucrose in an incubation pre-treatment plant. The main results show an increase of $12 \mathrm{v} \%$ in methane production from the industrial biogas plant when coupled with the anaerobic digester. This improvement can have significant economic advantages. In fact, this work shows that the net present value of the plant can increase about $30 \%$. The equity payback period can decrease to 5.8, compared to the value of 7 calculated for the reference scenario (i.e., anaerobic digestion without an incubator). The main risks of the investment are electricity export rate, initial costs, and fuel costs

Author Contributions: P.B. and F.F. designed the experiments; F.L. and V.P. managed the experimental tests and elaborated the data; S.M. and M.Z. helped in discussing the results together with F.F., P.B. and M.M.; and N.H. helped in formatting and further improving the paper.

Funding: This research was funded by POR-FESR funds 2016 of Emilia Romagna Region.

Acknowledgments: The authors would like to acknowledge the LIFE 16 ENV/IT/000547 project I-REXFO LIFE (http://irexfo.eu/). i-REXFO LIFE (LIFE16ENV/IT/000547) is a project funded by the EU under the LIFE 2016 program. The authors would like to thank the POR-FESR funds 2016 of Emilia Romagna Region and the collaboration of the startup Biobooster srl.

Conflicts of Interest: The authors declare no conflict of interest.

\section{References}

1. Shen, Y.; Linville, J.L.; Urgun-Demirtas, M.; Schoene, R.P.; Snyder, S.W. Producing pipeline-quality biomethane via anaerobic digestion of sludge amended with corn stover biochar with in-situ $\mathrm{CO}_{2}$ removal. Appl. Energy 2015, 158, 300-309. [CrossRef]

2. Mangwandi, C.; JiangTao, L.; Albadarin, A.B.; Allen, S.J; Walker, G.M. The variability in nutrient composition of Anaerobic Digestate granules produced from high shear granulation. Waste Manag 2013, 33, 33-42. [CrossRef] [PubMed]

3. Fabbri, D.; Torri, C. Linking pyrolysis and anaerobic digestion (Py-AD) for the conversion of lignocellulosic biomass. Curr. Opin. Biotechnol. 2016, 38, 167-173. [CrossRef] [PubMed]

4. Muhammad Nasir, I.; Mohd Ghazi, T.I.; Omar, R. Production of biogas from solid organic wastes through anaerobic digestion: a review. Appl. Microbiol. Biotechnol. 2012, 95, 321-329. [CrossRef]

5. Raposo, F.; Fernández-Cegrí, V.; De la Rubia, M.A.; Borja, R.; Béline, F.; Cavinato, C.; Demirer, G.; Fernández, B.; Fernández-Polanco, M.; Frigon, J.C.; et al. Biochemical methane potential (BMP) of solid organic substrates: evaluation of anaerobic biodegradability using data from an international interlaboratory study. J. Chem. Technol. Biotechnol. 2011, 86, 1088-1098. [CrossRef]

6. Ratanatamskul, C.; Wattanayommanaporn, O.; Yamamoto, K. An on-site prototype two-stage anaerobic digester for co-digestion of food waste and sewage sludge for biogas production from high-rise building. Int. Biodeterior. Biodegrad 2015, 102, 143-148. [CrossRef]

7. Mao, C.; Feng, Y.; Wang, X.; Ren, G. Review on research achievements of biogas from anaerobic digestion. Renew. Sustain. Energy Rev. 2015, 45, 540-555. [CrossRef]

8. Liu, Y.; Wachemo, A.C.; RongYuan, H.; Li, X. Anaerobic digestion performance and microbial community structure of corn stover in three stage continuously stirred tank reactors. Bioresour. Technol. 2019, 287. [CrossRef]

9. Kaparaju, P.; Ellegaard, L.; Angelidaki, I. Optimisation of biogas production from manure through serial digestion: Lab-scale and pilot-scale studies. Bioresour. Technol. 2008, 100, 701-709. [CrossRef]

10. Smith, D.P.; McCarty, P.L. Reduced product formation following perturbation of ethanol- and propionate-fed methanogenic CSTRs. Biotechnol. Bioengng. 1989, 34, 885-895. [CrossRef]

11. Babel, S.; Fukushi, K.; Sitanrassamee, B. Effect of acid speciation on solid waste liquefaction in an anaerobic acid digester. Water Res. 2004, 38, 2416-2422. [CrossRef] [PubMed]

12. Angelidaki, I.; Ahring, B.K. Effects of free long-chain fatty acids on thermophilic anaerobic digestion. Appl. Microbiol. Biotechnol. 1992, 37, 808-812. [CrossRef]

13. Boe, K.; Angelidaki, I. Serial CSTR digester configuration for improving biogas production from manure. Water Res. 2009, 43, 166-172. [PubMed] 
14. Gerlach, D.; Alleborn, N.; Baars, A.; Delgado, A.; Moritz, J.; Knorr, D. Numerical simulations of pulsed electric fields for food preservation: a review. Innovat. Food Sci. Emerg. Technol. 2008, 9, 408-417. [CrossRef]

15. Zheng, Y.; Zhao, J.; Xu, F.; Li, Y. Pretreatment of lignocellulosic biomass for enhanced biogas production. Prog. Energy Combust. Sci. 2014, 42, 35-53. [CrossRef]

16. Sambusiti, C.; Monlau, F.; Ficara, E.; Carrère, H.; Malpei, F. A comparison of different pre-treatments to increase methane production from two agricultural substrates. Appl. Energy 2013, 104, 62-70. [CrossRef]

17. Carrère, H.; Dumas, C.; Battimelli, A.; Batstone, D.J.; Delgenès, J.P.; Steyer, J.P.; Ferrer, I. Pretreatment methods to improve sludge anaerobic degradability: A review. J. Hazard Mater. 2010, 183, 1-15. [CrossRef]

18. Liu, H.; Chen, Y. Enhanced methane production from food waste using cysteine to increase biotransformation of 1-monosaccharide, volatile fatty acids, and biohydrogen. Environ. Sci. Technol. 2018, 52, 3777-3785. [CrossRef]

19. Luo, C.; Lü, F.; Shao, L.; He, P. Application of eco-compatible biochar in anaerobic digestion to relieve acid stress and promote the selective colonization of functional microbes. Water Res. 2015, 68, 710-718. [CrossRef]

20. Yin, Q.; Yang, S.; Wang, Z.; Xing, L.; Wu, G. Clarifying electron transfer and metagenomic analysis of microbial community in the methane production process with the addition of ferroferric oxide. Chem. Eng. J. 2018, 333, 216-225. [CrossRef]

21. Lü, F.; Luo, C.; Shao, L.; He, P. Biochar alleviates combined stress of ammonium and acids by firstly enriching Methanosaeta and then Methanosarcina. Water Res. 2016, 90, 34-43. [CrossRef] [PubMed]

22. Luo, J.; Chen, Y.; Feng, L. Polycyclic aromatic hydrocarbon affects acetic acid production during anaerobic fermentation of waste activated sludge by altering activity and viability of acetogen. Environ. Sci. Technol. 2016, 50, 6921-6929. [CrossRef] [PubMed]

23. Mumme, J.; Srocke, F.; Heeg, K.; Werner, M. Use of biochars in anaerobic digestion. Bioresour. Technol. 2014, 164, 189-197. [CrossRef] [PubMed]

24. Fantozzi, F.; Buratti, C. Biogas production from different substrates in an experimental Continuously Stirred Tank Reactor anaerobic digester. Bioresour. Technol. 2009, 100, 5783-5789. [CrossRef] [PubMed]

25. Fantozzi, F.; Buratti, C. Anaerobic digestion of mechanically treated OFMSW: Experimental data on biogas/methane production and residues characterization. Bioresource Technol. 2011, 102, 8885-8892. [CrossRef] [PubMed]

26. CEN/TS 14774 Methods for determination of moisture content-Oven dry method-Part 3: Moisture in the analysis sample. Available online: http://store.uni.com/catalogo/index.php/cen-ts-14774-2-2004?josso_back_ to=http://store.uni.com/josso-security-check.php\&josso_cmd=login_optional\&josso_partnerapp_host=st ore.uni.com (accessed on 2 December 2019).

27. CEN/TS 14775 Method for the determination of ash content. Available online: http://store.uni.com/catalogo /uni-cen-ts-14775-2005 (accessed on 2 December 2019).

28. CEN/TS 15148 Solid Biofuels-Method for the determination of the content of volatile matter. Available online: http://store.uni.com/catalogo/index.php/uni-cen-ts-15148-2006 (accessed on 2 December 2019).

29. Budzianowski, W.M.; Budzianowska, D.A. Economic analysis of biomethane and bioelectricity generation from biogas using different support schemes and plant configurations. Energy 2015, 88, 658-666. [CrossRef]

30. Sgroi, F.; Foderà, M.; Di Trapani, A.M.; Tudisca, S.; Testa, R. Economic evaluation of biogas plant size utilizing giant reed. Renew. Sustain. Energy Rev. 2015, 49, 403-409. [CrossRef]

31. Available online: https://www2.deloitte.com/content/dam/Deloitte/global/Documents/Tax/dttl-tax-italyhigh lights-2019.pdf?nc=1 (accessed on 2 December 2019).

32. Available online: https://tradingeconomics.com/italy/bank-lending-rate (accessed on 2 December 2019).

33. Available online: http://www.crpa.it/media/documents/crpa_www/Convegni/20130314_BiogasBiometano_R A/Ragazzoni_RA_14-3-2013.pdf (accessed on 2 December 2019).

(C) 2019 by the authors. Licensee MDPI, Basel, Switzerland. This article is an open access article distributed under the terms and conditions of the Creative Commons Attribution (CC BY) license (http://creativecommons.org/licenses/by/4.0/). 